\title{
Situation analysis of the sexual and reproductive health and HIV risks and prevention needs of older orphaned and vulnerable children in Nyanza Province, Kenya
}

Milka Juma

Ian Askew

Population Council

Alan Ferguson

Follow this and additional works at: https://knowledgecommons.popcouncil.org/departments_sbsr-rh

Part of the Demography, Population, and Ecology Commons, Family, Life Course, and Society Commons, International Public Health Commons, Maternal and Child Health Commons, and the Medicine and Health Commons

How does access to this work benefit you? Let us know!

\section{Recommended Citation}

Juma, Milka, Ian Askew, and Alan Ferguson. 2007. "Situation analysis of the sexual and reproductive health and HIV risks and prevention needs of older orphaned and vulnerable children in Nyanza Province, Kenya." Nairobi: Population Council and Constella Futures. 


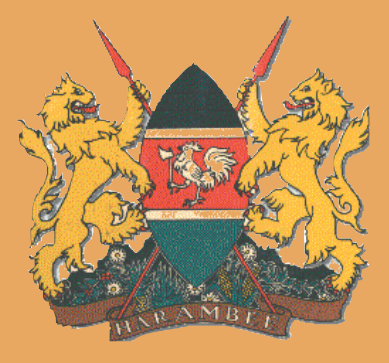

Situation Analysis of the Sexual and Reproductive Health and HIV Risks and Prevention Needs of Older Orphaned and Vulnerable Children in Nyanza Province, Kenya 


\title{
Situation Analysis of the Sexual and Reproductive Health and HIV Risks and Prevention Needs of Older Orphaned and Vulnerable Children in Nyanza Province, Kenya
}

\author{
Population Council \\ Milka Juma \\ Ian Askew \\ Constella-Futures
}

Alan Ferguson

\begin{abstract}
On behalf of
Department of Children's Services, Office of the Vice President and Ministry of Home Affairs, Government of Kenya
\end{abstract}

March 2007

This study was funded by the Department for International Development (DFID) through ConstellaFutures and implemented by the Population Council. The opinions expressed herein are those of the authors and do not necessarily reflect the views of DFID, Constella-Futures or the Department of Children's Services of the Ministry of Home Affairs. 


\section{TABLE OF CONTENTS}

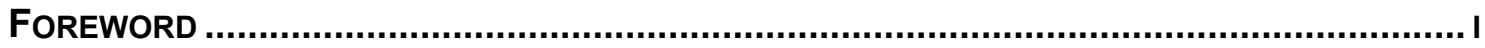

ACKNOWLEDGEMENTS ............................................................................................. II

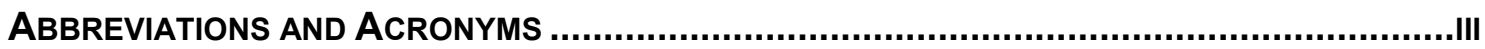

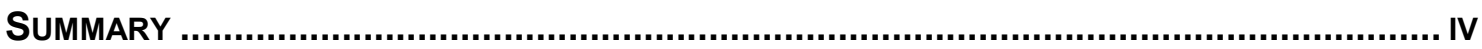

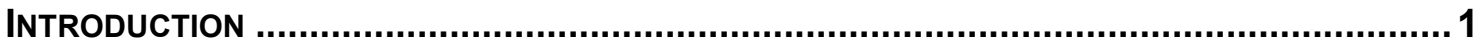

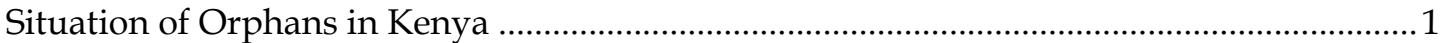

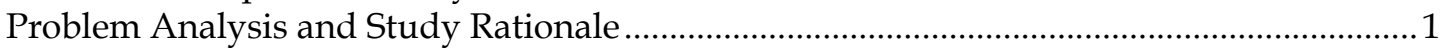

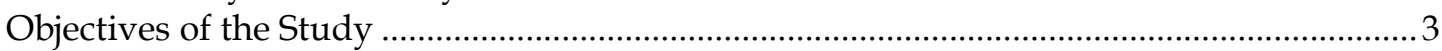

RESEARCH METHOdOLOGY.................................................................................... 4

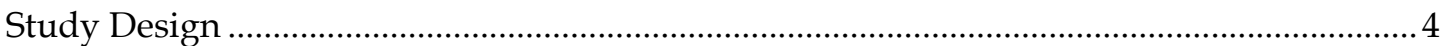

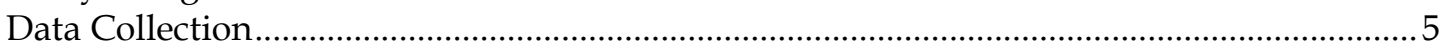

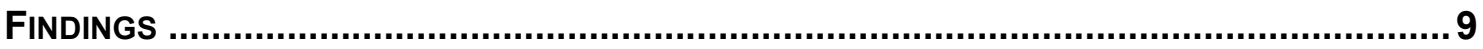

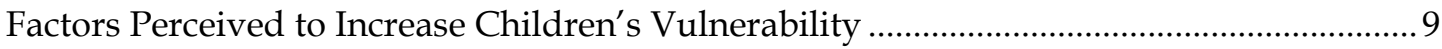

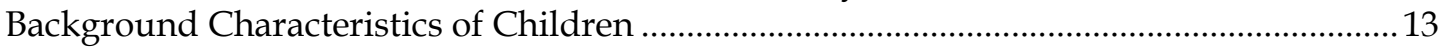

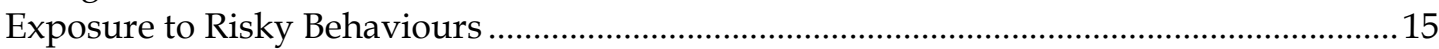

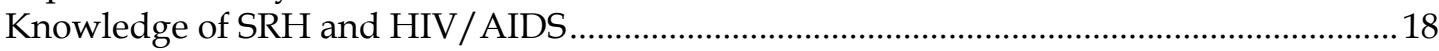

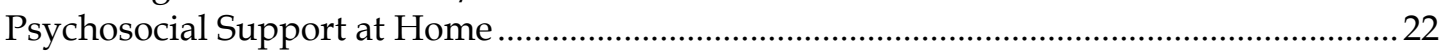

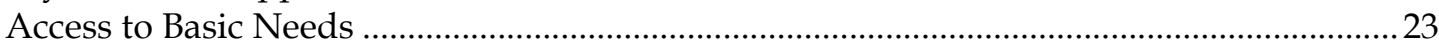

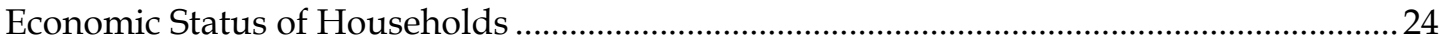

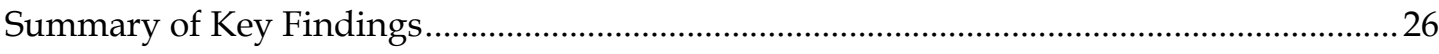

Conclusions and Programmatic Recommendations ...........................................28

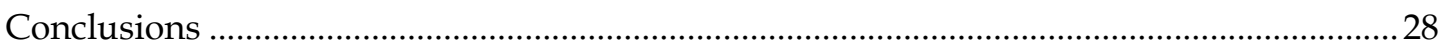

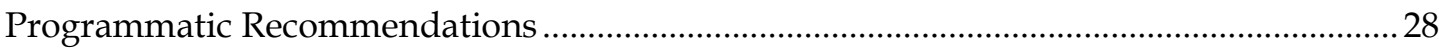

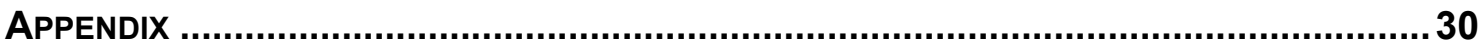

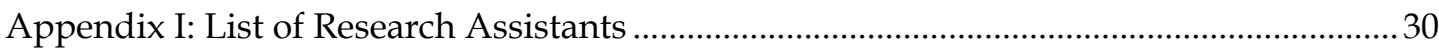

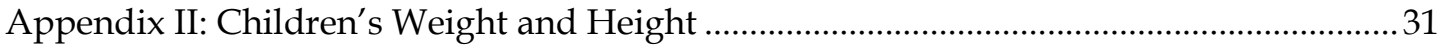




\section{FOREWORD}

Children aged 10-17 comprise a segment of the population faced with unique sexual and reproductive health $(\mathrm{SRH})$ challenges including poor access to SRH information and services. However, national data on the SRH needs of younger children (10-14 years) in this age group is scarce. According to the 2003 Kenya Demographic and Health Survey (KDHS), females aged 15 to 24 are three times more likely to be HIV-infected than their male counterparts. Sexual activity begins at an early age with few young people reporting use of any preventive/protective measure, thus increasing their risk to pregnancy and sexually transmitted infections (STIs) including HIV. These study findings are, however, not disaggregated by orphan status. Thus there is a need to determine whether older Kenyan children who are orphaned or vulnerable are at greater risk of engaging in risky sexual behaviours than non-orphans.

HIV/AIDS has resulted in increased numbers of orphaned and vulnerable children (OVC) in Kenya. The 2003 KDHS shows an estimated 11 percent $(1.7 \mathrm{~m})$ of all Kenyan children less than 15 years had been orphaned, compared to nine percent in 1998. Nyanza Province has the highest rates of HIV infection and the highest level of orphanhood in Kenya with up to 40 percent of children less than 18 years orphaned and the proportion is growing. The growing number of OVC in one of the most impoverished provinces underscores the need to better understand their situation to make programs for this segment of children more targeted.

The Office of the Vice President and Ministry of Home Affairs (OVP/MOHA) through the Department of Children's Services is responsible for formulating policies related to children and coordinating their implementation as well as initiatives aimed at improving the lives of children. Among other initiatives to address the needs of OVC, the MOHA has set up the National Steering Committee on OVC facilitated by the Department of Children's Services; drafted the National Policy on Orphans and Vulnerable Children; and currently piloting a cash transfer (CT) program in some districts to strengthening the capacity of households to take care of OVC. The Department of Children's Services therefore commissioned this study, conducted in Nyanza Province, to provide a better understanding of OVC SRH needs to inform such initiatives. The study design facilitates comparison of the situation of orphans and non-orphans in Nyanza. What emerges is an overall picture of unmet needs in SRH for all young people, in which are embedded particularly specialized psycho-social and economic needs for the orphaned youth. Many of the findings are distressing, but need to be acknowledged as a challenge that requires our immediate and effective response.

I urge all the stakeholders to ensure that these study findings are utilized to strengthen programs for OVCs and other children. The OVP/MOHA will continue to enhance an enabling environment for the provision of services and programs aimed at improving the lives of Kenyan children now and in the future.

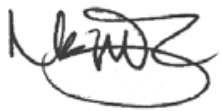

Amb. Nancy Kirui, CBS

Permanent Secretary

Office of the Vice President and

Ministry of Home Affairs 


\section{ACKNOWLEDGEMENTS}

The authors would like to thank the Department of Children's Services in the Office of the Vice President and Ministry of Home Affairs and the National Steering Committee on Orphans and Vulnerable Children (OVC) for the opportunity to conduct this study. We would like to acknowledge the advice and support throughout the study from Ahmed Hussein, Director, and Margaret Basigwa, Deputy Director, of the Department of Children's Services, and from the OVC Secretariat in the Department, including Caren Ogoti, Mary Mbuga, Daniel Musembi and Joseph Ajwang. The team is grateful to the Nyanza Province Children's Department staff including Elly Akach, Charles Ondogo, Jane Rono, Beatrice Obutu, Julius Ngoko and Otijom Omuse, for their assistance that facilitated smooth data collection in their respective districts.

We are indebted to George Odingo for supervising data collection and assistance in analysing the qualitative and quantitative data. This study would not have been possible without the determination and commitment of the talented interviewers and professional counsellors who collected the data (names in Appendix I). Special thanks are given to the professional counsellors for ensuring that no child suffered any adverse effect resulting from the interviews by providing immediate counselling to children who found certain questions stressful.

Our special gratitude goes to the community leaders from all study sites for welcoming and introducing the data collectors to their communities. We sincerely thank the community members for their willingness to participate in the study and for the invaluable information provided. We would like to especially thank all parents and guardians for allowing us to interview their children.

Many thanks go to Katie Schenk of the Population Council for providing invaluable comments on earlier versions of this report. Our appreciation also goes to Diana Mwangi, Phillisters Obunga, and Janet Munyasya, all of Population Council, Nairobi for their respective administrative support throughout the study.

Finally we would like to thank the Department for International Development (DFID) through the Constella-Futures HAPAC3 programme for providing financial support for this project. 


\section{ABBREVIATIONS AND ACRONYMS}

$\begin{array}{ll}\text { AAC } & \text { Area Advisory Council } \\ \text { AIDS } & \text { acquired immune deficiency syndrome } \\ \text { CACC } & \text { Constituency AIDS Control Council } \\ \text { CBS } & \text { Central Bureau of Statistics } \\ \text { CCT } & \text { conditional cash transfer } \\ \text { DCO } & \text { District Children's Officer } \\ \text { DFID } & \text { Department for International Development } \\ \text { DHMT } & \text { District Health Management Team } \\ \text { FGD } & \text { focus group discussion } \\ \text { HIV } & \text { human immunodeficiency virus } \\ \text { KDHS } & \text { Kenya Demographic and Health Survey } \\ \text { IDI } & \text { In-depth Interviews } \\ \text { KII } & \text { Key Informant Interview } \\ \text { MOH } & \text { Ministry of Health } \\ \text { MOHA } & \text { Ministry of Home Affairs } \\ \text { NACC } & \text { National AIDS Control Council } \\ \text { OVC } & \text { Orphans and Vulnerable Children } \\ \text { SPSS } & \text { Statistical Package for Social Sciences } \\ \text { SRH } & \text { Sexual and Reproductive Health } \\ \text { STI } & \text { Sexually Transmitted infections } \\ \text { UNICEF } & \text { United Nations Children's Fund } \\ & \end{array}$




\section{SUMMARY}

The increasing number of children in Kenya who are orphaned or made vulnerable (OVC) from HIV / AIDS and other factors calls for a holistic understanding of their situation so that programmes to address their needs be designed to be effective and equitable. This is especially important for those areas hardest hit by the HIV/AIDS pandemic, such as Nyanza Province where up to 40 percent of children are orphaned and where one-third of all Kenyan orphans live. Little is known about the vulnerabilities of older orphans to risky sexual behaviour, and whether they are any more vulnerable than non-orphans, although evidence from countries in the region indicates that male and female orphans are more likely than non-orphans to engage in sex at a younger age and to engage in more risky behaviours.

With support from development partners including DFID and UNICEF, the Department of Children's Services in the Ministry of Home Affairs has initiated a cash transfer (CT) program to households taking care of OVC. The main objective of the CT program is to provide a social protection system through regular cash transfer to households living with OVC in order to encourage fostering and retention of OVC within their families and communities and to promote their human capital development. A central concern to the Department is how the programme could minimize any sexual and reproductive health (SRH) vulnerabilities of OVC. This study was commissioned by the Department through Constella Futures to provide a better understanding of the situation of OVC in Nyanza Province and of the opportunities to reduce OVC vulnerability.

The study collected data over the period April - August 2006 in four of the districts in Nyanza Province where the CT program is being piloted: Kisumu, Migori, Homa Bay and Suba. Qualitative data were collected from purposively selected groups of adult and children respondents to elicit community perceptions of vulnerabilities to SRH and HIV risks. A household questionnaire survey was carried out among almost 1,200 children aged 10-17 years, including orphans and non-orphans, to describe their living situations, knowledge and behaviours concerning sexuality. Key findings were as follows.

- Over one third (35\%) of all children were orphaned, with 11 percent of all children having neither a living mother nor father ("double orphans"). Whereas most non-orphans live in father-headed households, most orphans live in mother-headed households or with a grandparent or aunt/uncle; only half of the maternal orphans live with their father.

- Virtually all (97\%) orphans and non-orphans were currently in school, with the vast majority $(88 \%)$ in primary school. Less than one in five children had engaged in income generating activities recently, although orphans were slightly more likely to have done so than non-orphans.

- Half of all older boys and more than one third of older girls had ever had sex, and orphans were more likely than non-orphans to have ever done so. Girls who 
had lost their mothers were considerably more likely to have had sex than girls whose mothers were still alive.

- The average age at first sex, for those who had already had sex, was 12.5 years for orphan and non-orphan boys, whereas for non-orphan girls it was 13.8 years, but 13.2 years for orphan girls. For those who reported being sexually active, the average number of partners was two.

- For the majority of all sexually experienced girls, first sex was non-consensual. However, orphaned girls were more likely than girls who had not been orphaned to have had sex willingly the first time.

- Boys whose mother had died are much more likely than other boys to report having first sex with someone older and having paid for sex.

- One half of all sexually active girls reported having ever engaged in transactional sex, with slightly more orphans than non-orphans.

- Unprotected sex was the norm for all sexually active children, and both male and female orphans were significantly less likely than non-orphans to have used a condom at last sex.

- Although awareness of HIV/AIDS was universal, most children, regardless of age, sex or orphan status, had limited knowledge of transmission modes and prevention measures. Most children knew very little about fertility and pregnancy prevention.

- Schools were the most frequently mentioned source of information about SRH and HIV/AIDS for all children, with parents/guardians and peers also being mentioned. Parents are the preferred source of information, for both adults and children, and especially for non-orphans, but over half the children are concerned that they have inadequate knowledge.

- Orphans and non-orphans felt equally susceptible to peer pressure, but orphans, and especially maternal orphans, were more likely to have engaged in risky social behaviours, such as attending night activities and drinking alcohol.

- No differences in nutritional status, as measured by height and weight for age, were found between orphans and non-orphans.

- Lack of supervision and/or loving care by parents/guardians was perhaps the key factor that increases vulnerability to risky behaviour by children, and orphans were felt to be at increased risk because of this. Orphaned girls, and especially those who had lost their mothers, were the least likely to feel they had such support.

- Many children reported not being able to access a range of basic necessities, and orphans were more likely to report being deprived basic necessities. Overall, there was no difference, however, in the economic status of households with or without orphans, although the poorest of the poor were slightly more likely to have an orphan. 
In summary, there are few major differences overall between orphans and nonorphans in terms of their living situation conditions, as many lack basic needs and live in households of poor or average economic status. All children are equally poorly informed about SRH issues and preventive behaviours; as one girl noted: "Orphans are just like us. We all don't have adequate information on reproductive health and $H I V^{\prime \prime}$. Schools seem to be easiest and most appropriate point of contact for reaching all children with education, although parents are the preferred source but would need to increase their knowledge to be able to provide credible advice. Orphans, and especially maternal orphans, are more likely to become sexually active. Indeed, for both girls and boys whose mother has died, there is some evidence that they may be engaging in sex to seek love and affection that they may not be getting at home, and that a lack of supervision and guidance may facilitate this by allowing them to engage in risky behaviours.

Because the proportions of children reporting being sexually active were relatively small, the sample sizes are only large enough to be able to make tentative conclusions about sexual behaviours and risks. Larger samples collected through further research are needed for more definitive and detailed analyses, which would provide a better understanding of the factors determining and differentiating the sexual vulnerabilities of orphans and non-orphans.

Strategies are urgently needed to reduce non-consensual / forced sex by boys and men against all girls. This vulnerability affects all girls, regardless of orphan status indeed, non-orphan girls are more likely to report non-consensual first sex with a stranger than orphan girls - and so the role of an orphan support programme in addressing this particular vulnerability is not clear.

Transactional sex is highly prevalent among all girls, and because this risky behaviour is not necessarily more acute among orphans, an orphan support programme may not be the appropriate mechanism through which it could be reduced. Orphans of both sexes do appear, however, to have somewhat less access to basic needs than non-orphans, and so a cash transfer mechanism that increases their access to such necessities has the potential to reduce an economic motivation to engage in sex.

As both orphans and non-orphans are equally likely to be in school, and schools are an accepted channel for communicating information about risk reduction behaviours, any programme that strengthens the quantity and quality of education about SRH and builds appropriate skills to enable preventive behaviours within the school environment would contribute to reducing the vulnerability of all children, including orphans. Parents/guardians are a preferred source for such information, and so efforts are needed to ensure that they are able to educate the children they care for. 
The key recommendation emerging from this evidence is that guardians of orphans, and particularly orphans whose mother has died, need to be aware of the need to ensure that these children receive adequate support, guidance and love to reduce possibility of them seeking sexual relationships that may put them at risk. How such a recommendation can be implemented through a CT or other orphan-support programme is a major challenge, however.

One possibility that needs to be explored further is that guardians may give, or be perceived to give, orphans less love and guidance if they are struggling to support the family as a whole, and perceive that the child is simply another mouth to feed. In such cases, the CT program needs to ensure that it really is reaching the poorest of the poor (as it is mandated to) in order to alleviate any possible additional stress in households that are already struggling to survive.

Cash transfers could create divisions within communities, however, if those households with orphans and receiving cash transfers are no worse off economically than those without orphans, as seems to be the situation in Nyanza Province. In such situations, it may be necessary to ensure that 'means testing' is undertaken rigorously to ensure that those households benefiting economic support are truly the most needy. 



\section{INTRODUCTION}

\section{Situation of Orphans in Kenya}

The number of Kenyan children who are orphaned or made vulnerable has increased as a result of AIDS. An orphan is defined as a child aged below 18 years for whom one or both parents have died for whatever reason. For the purposes of this study, an older orphan is defined as any child aged 10-17 years for whom one or both parents has died, and who is not married. In this study a vulnerable child is a child living in a household with a chronically ill person, whether parent or not. In 2003 , an estimated 11 percent $(1.7 \mathrm{~m})$ of all Kenyan children less than 15 years had been orphaned according to the Kenya Demographic and Health Survey (KDHS) ${ }^{1}$, compared to nine percent in 1998. Of these, 37 percent are estimated to have been orphaned due to AIDS2. Nationally, nine percent of children have lost their father, four percent have lost their mother, and two percent have lost both parents.

According to the 2003 KDHS, approximately 19 percent of children under 15 in Nyanza Province have lost one or both parents, the highest level in Kenya. Other studies conducted in the province show that up to 40 percent of children are orphaned and the proportion is growing ${ }^{3}$. A recent report by UNICEF indicated that Nyanza Province is home to approximately 500,000 orphans, which is about onethird of all orphans in Kenya ${ }^{4}$. This high number of orphaned children represents a tip of the iceberg, with many children also remaining vulnerable due to parental illness associated with HIV/ AIDS. Such children may be extremely vulnerable and often assume the responsibilities of their ailing parents.

\section{Problem Analysis and Study Rationale}

Orphans have to live without full parental care and guidance. Orphaned and vulnerable children (OVC) often live with other relatives or with non-relatives, as they cannot fend for themselves, although a small proportion does live on their own. Without care and support of one or more responsible adults, orphaned children may be less able to access basic needs (such as shelter, food and clothing) and education, and may also be more vulnerable to physical and sexual abuse, or to engaging in risky behaviours that can adversely affect their health and well-being.

Some OVC, especially females, may be forced into or opt for early marriage, or may resort to having sex in exchange for money, other material items or favours (termed

\footnotetext{
1 CBS, MOH, and ORC Macro (2004) Kenya Demographic and Health Survey, 2003 Calverton, Maryland, USA: CBS, MOH and Macro.

2 UNAIDS/UNICEF/USAID (2004). Children on the Brink, UNICEF, New York, USA

3 Nyambedha E. et al., (2001) "Policy implications of the inadequate support systems for orphans in western Kenya", Health Policy: 58:83-96I; Center for Study of Adolescence (2003) The Situation of Young People in Kenya, CSA, Nairobi, Kenya.

$4 \quad$ UNICEF Kenya (2004). UNICEF Kenya 2004 Report.
} 
'transactional sex') as survival strategies, which may expose them to risks of infection with HIV or other sexually transmitted infections (STI), and to early pregnancy and early childbearing.

In Kenya, three percent of females aged 15-19 years are HIV-infected, whereas 0.4 percent of males in this age group are HIV-positive. Nyanza Province has the highest HIV prevalence rates among female youth aged 15-24 in Kenya (15\%) and $2 \%$ among males, a rate similar to other areas ${ }^{5}$. The KDHS shows also that in Nyanza Province, sexual activity begins earlier than any other part of the country, on average at 15.9 years for girls and 16.4 for boys, and that adolescents living in rural areas start having sex at a younger age than those living in urban areas.

It is not known whether orphans and other vulnerable children (of either sex) in Kenya are at greater risk of engaging in risky sexual behaviours, such as early sexual initiation, early marriage, transactional sex, coercive sex and unprotected sex, especially with high-risk individuals. Studies in other countries have found that both male and female orphans are significantly more likely than non-orphans to have engaged in sex; a study in South Africa for example, found that orphans were one and a half times more likely than non-orphans to have had sex, and were more likely to start at a younger age ${ }^{6}$. Another South African study found that relative to nonorphans, paternal orphaned males and females were more likely to start sex earlier 7 . Gregson S. et al (2005) found female orphans in eastern Zimbabwe had higher HIV prevalence, and more common experience of STI and teenage pregnancy than nonorphans. High proportions of HIV infections, STIs and teenage pregnancies were attributed to maternal orphanhood and parental HIV status ${ }^{8}$. Moreover, OVCs may also have limited opportunities to learn about HIV/ AIDS and other sexual and reproductive health (SRH) issues if they are not living with caring parents or guardians, attending school, or have access to sources of such information, through print materials, including newspapers, radio or television.

The Children's Department of the Kenyan Ministry of Home Affairs (MOHA), with technical and financial support from DFID and UNICEF and funding from the $\mathrm{MOHA}$, is piloting an innovative programme in some districts in Nyanza Province that seeks to improve the well-being of OVCs through cash transfers. The main aim of the OVC-CT program is to provide a social protection system through regular cash transfers to families living with OVC in order to encourage fostering and retention of OVC within their families and communities and to promote their human capital development. Households that qualify for cash transfer are those that are extremely poor, have an OVC and no members are beneficiaries of other CT

\footnotetext{
$5 \quad$ CBS et al op cit

6 Thurman T. et al (2006). "Sexual risk behavior among South African Adolescents: Is orphan status a factor?” AIDS and Behavior 10(6): 627-635.

$7 \quad$ Hallman, K. (2006). "Orphanhood and adolescent HIV risk behaviors in KwaZulu-Natal, South Africa”, Paper presented at the Population Association of America 2006 Annual Meeting.

$8 \quad$ Gregson S. et al (2005). "HIV infection and reproductive health in teenage women orphaned and made vulnerable by AIDS in Zimbabwe”. AIDS Care. 2005 Oct; 17(7):785-94
} 
programs. Central to this programme of support is the concern of the Children's Department that any sexual and reproductive health vulnerabilities of OVCs be minimised. How best this can be done through OVC support programmes such as this one can only be determined by having a thorough understanding of the situation in which OVCs live in Nyanza Province, and of what opportunities exist to provide this support that would be both effective and culturally acceptable.

To guide its programming in this area, the Children's Department requested Constella Futures to undertake a situation analysis of the reproductive health and HIV prevention needs of older OVC in Nyanza Province. With financial support from DFID, Constella Futures commissioned the Population Council to undertake a study to determine the extent to which older OVCs (aged 10-17 years) may be at greater risk than non-orphans, to specify the factors that may increase their vulnerability, and in consultation with communities in the study areas, use the findings to identify possible interventions that address the identified needs. The study was carried out in the four districts of Nyanza Province (Migori, Homa Bay, Suba and Kisumu) in which the Children's Department is introducing the OVC support programme over the period April - August 2006.

\section{Objectives of the Study}

The overall objective of the study was to conduct a participatory situation analysis and needs assessment of the SRH and HIV vulnerabilities of older OVC aged 10-17 years in four districts in Nyanza Province in which the conditional cash transfer for OVC is being piloted. Specifically, the study sought to:

1. Conduct a participatory situation analysis of the SRH and HIV vulnerabilities of older OVC with respect to their SRH and HIV knowledge and behaviours;

sources of information, health-seeking behaviour; and health and nutrition status by age and gender;

2. Develop criteria that may be used to assess vulnerability of older OVC at community level;

3. Communicate programmatic implications of the findings to the National Steering Committee on OVC, and national and district stakeholders;

4. Identify and outline appropriate intervention for OVC aged 10-13 and 14-17 in relation to SRH promotion and HIV prevention and treatment and general care. 


\section{RESEARCH METHODOLOGY}

\section{Study Design}

The study was conducted in two constituencies in each of the four study districts (total of eight constituencies) where the CCT project is being implemented. The Constituency AIDS Control Councils (CACCs) within the National AIDS Control Council (NACC) support all AIDS-related programs within their constituencies. The Area Advisory Councils (AAC), established by the Children's Department, supervise OVC activities within their respective districts. AAC comprises of the District Commissioner and a representative from all government departments, NGOs and civil society organizations dealing with children's issues. Each AAC has about 25 members. Within the eight constituencies, one Location was randomly selected, and within each Location one sub-Location was then randomly selected for the research.

The situation analysis was conducted in two stages. First, qualitative data were collected from purposively selected groups of respondents to generate community perceptions of children's vulnerabilities to SRH and HIV risks, and whether there are any perceived differences between OVCs and non-orphans. Groups interviewed included children (both orphans and non-orphans), parents/guardians, community leaders, service providers and AAC representatives (see Table 1).

Secondly, this information was then used to guide the design of a household-level questionnaire survey of children aged 10-17 years. The study sample included both orphans and nonorphans to determine whether there are any differences between them, and which factors are likely to increase the vulnerability of orphans compared with other children. To be able to undertake statistically meaningful analyses, a total of 1,200 girls and boys aged 10-13 and 14-17 years were to be recruited across the four districts, subdivided into 300 per age-sex group.
Table 1: Respondents for qualitative data collection

\begin{tabular}{|r|c|c|}
\hline Category & $\begin{array}{c}\text { No. of } \\
\text { groups }\end{array}$ & $\begin{array}{c}\text { No. of } \\
\text { participants }\end{array}$ \\
\hline Focus group discussions & & \\
Female parents/guardians & 3 & 29 \\
Male parents/guardians & 2 & 20 \\
Girls 14-17 years & 3 & 24 \\
Boys 14-17 years & 5 & 40 \\
Total & 13 & 113 \\
\hline In-depth interviews & & \\
Community leader & - & 4 \\
AAC Representative & - & 3 \\
Health/OVC service provider & - & 4 \\
Children & - & 2 \\
Total & - & 13 \\
\hline Free-listing & & \\
Girls 10-13 years & 7 & 35 \\
Boys 10-13 years & 7 & 35 \\
Total & 14 & 70 \\
\hline
\end{tabular}

Data from the Nyanza Provincial office of the Central Bureau of Statistics (CBS) indicated that 22-23 percent of the population in each of the study districts is aged 10-17 years, and so the sample of 1,200 adolescents was distributed proportionally to the population of children aged 10-17 years in each of the eight sub-locations (Table 2). 
Table 2: Study Sites and expected sample

\begin{tabular}{|c|c|c|c|c|c|}
\hline District & Constituency & Location & $\begin{array}{c}\text { Sub- } \\
\text { Location }\end{array}$ & $\begin{array}{l}\text { Est. pop. aged } \\
10-17 \text { years }\end{array}$ & $\begin{array}{l}\text { Expected } \\
\text { sample } \\
\text { size }\end{array}$ \\
\hline \multirow{2}{*}{ Kisumu } & Kisumu Town West & Township & Kaloleni & 2,945 & 257 \\
\hline & Kisumu Rural & South Central Seme & West Othany & 845 & 74 \\
\hline \multirow{2}{*}{ Migori } & Uriri & West Kanyamkago & Kajulu 1B & 1,357 & 118 \\
\hline & Migori & Suna Ragana & Marindi & 2,307 & 201 \\
\hline \multirow{2}{*}{$\begin{array}{l}\text { Homa } \\
\text { Bay }\end{array}$} & Rangwe & Township & Arujo & 4,091 & 357 \\
\hline & Ndhiwa & Kwabwai & Kachuth & 629 & 55 \\
\hline \multirow{3}{*}{ Suba } & Mbita & Gembe West & Kasgunga C & 610 & 53 \\
\hline & Gwassi & Gwassi East & Kibwer & 972 & 85 \\
\hline & & & Total: & 13,756 & 1,200 \\
\hline
\end{tabular}

With an estimated 35 percent of 10-17 year old children being orphaned in Nyanza Province, a corresponding sample size among those interviewed would be sufficiently large to allow statistical comparisons to be made between orphans and non-orphans, thereby enabling the analysis to determine whether any meaningful differences exist.

Households were randomly selected from CBS enumeration clusters within each sub-location, and one adolescent from one of the four age-sex categories was interviewed per household. If there was more than one eligible adolescent, interviewers randomly selected one from among them through assigning each eligible respondent a number. Each number was written on a separate piece of paper that was wrapped, all put together and one selected.

Because of the importance of ensuring that children are protected from emotional or other stress when collecting sensitive information from them ${ }^{9}$, the study design and data collection procedures were reviewed and approved by the Ethical Review Committee of Kenyatta National Hospital and the Institutional Review Board of the Population Council.

\section{Data Collection}

Unmarried adolescents under 18 years old are considered legal minors in Kenya. During the recruitment process, therefore, the parent or guardian for all selected children was asked to give their permission; if they approved, the child was then asked for their informed assent to participate. No parents/guardians refused to give permission for a child to be interviewed, and all children gave their assent, but the sample recruited was only 97 percent of the intended size because of absence from the home of the randomly selected respondents at the time of survey. The sensitive nature of the data to be collected was explained to the adolescent when obtaining

$9 \quad$ Schenk K. and J. Williams (2005) Ethical Approaches to Gathering Information from Children and Adolescents in International Settings: Guidelines and Resources, Washington, DC: Population Council. 
their assent so that they could decide whether or not they would be comfortable participating in the interview. Anyone not feeling comfortable was under no pressure to participate. One-quarter of the interviewers were trained and experienced counsellors, who were available to provide immediate counselling and referral to any adolescent who was observed to be suffering some kind of distress. Precaution was taken to keep confidentiality. Interviews were held in private with the adolescent and they were assured that the information they gave would be confidential. The signed assent forms were stored separately from the rest of the instrument. No names were recorded on the individual interviews; instead, individual identification codes were used on the cover pages of questionnaires.

Qualitative data collection tools: Purposive samples of respondents were selected to participate based on their availability, willingness and capacity to participate in the discussions. Community leaders facilitated recruitment of participants who were verified by the interviewers. Focus group discussions (FGDs) were undertaken with guardians and children aged 14-17 years. For the younger adolescents aged 10-13 years, a free listing guide ${ }^{10}$ was used; two groups of children per Location (five girls and five boys) participated in the free-listing exercise. Children worked in groups of five, separately by sex. In-depth interview (IDI) guides were used with community leaders, service providers, AAC members and children. These tools were used to elicit participants' perceptions of the personal, social and communal factors that may make adolescents vulnerable to risky SRH behaviours and outcomes, and their perceptions of whether there are any differences by sex, orphan status, age, or other factors. The tools also gathered information on suggestions as to what could be done to address the needs identified.

Individual questionnaires: Two pre-coded, interviewer administered, questionnaires were used: one for 10-13 year-old children, and another for 14-17 year old children. Instruments were carefully designed and reviewed by community members including young adolescents, local experts working with OVC and AAC members to ensure they were age-appropriate. Both questionnaires had the following sections:

- Socio-demographic characteristics

- Sources of SRH and HIV/AIDS information

- Care, love and support

- SRH and HIV / AIDS knowledge

- Risk exposure

- Younger children: peer pressure and attending night activities

- Older children: peer pressure, attending night activities, sexual experience and behaviour, transactional sex, forced sex, use of prevention methods, drug abuse, and personal risk perception

- Nutritional status, as measured by weight (scales) and height (tape measure)

- Health seeking behaviour and perception of health status. on issues affecting their lives with minimal facilitation. Children listed their perspectives on factors that may make them vulnerable to SRH risks and HIV infection, and prioritized them in terms of importance through discussions among themselves. Facilitators recorded the responses for those having difficulty with writing at the initial listing. 
The questionnaire for children aged 14-17 years had additional sections with questions that were felt to be inappropriate and potentially stressful for younger children, as follows:

$\checkmark$ SRH and HIV/AIDS knowledge about a woman's fertile period, pregnancy prevention, family planning methods, and sexually transmitted infections;

$\checkmark$ Risk exposure, including sexual experience and behaviour, transactional sex, forced sex, use of prevention methods, drug abuse, and personal risk perception;

$\checkmark$ Experiences with adverse consequence of unprotected sex;

$\checkmark$ Experience with HIV testing.

Data collection procedures: A team of eight experienced discussion facilitators, working together in each sub-location, collected the qualitative data after three days of training. The tools were field-tested and revised before data were collected in April 2006. For the questionnaire survey, 20 interviewers, comprising 15 experienced interviewers and five trained and experienced OVC counsellors, were recruited and trained for five days in questionnaire administration, procedures for obtaining informed consent, and communication skills.

The training emphasized how to interact with children according to ethical principles. Given the likelihood that asking sensitive questions about sexual experiences, including experiences of abuse, infection and pregnancy, may be emotionally stressful to some respondents, particular attention was paid to training interviewers to recognize actual or potential problems as they emerged. Moreover, as sexual and other forms of abuse are criminal acts and an abuse of basic rights, strict procedures were developed in consultation with the Children's Department and the ethical review board so that reports of such experiences could be handled appropriately. Interviewers who came across children who mentioned having been sexually abused during the interviews, were instructed to inform the District Children's Officer (DCO) of the total number of cases mentioned altogether in their district, and the child or their guardian would have the option of reporting the suspected abuse directly to the authorities. The experienced OVC counsellors participating in the study would be made available to provide counseling to any children requiring such psychological support, but would not be required to report the situation to the authorities.

No cases of abuse were mentioned explicitly during the data collection. However, interviewers reported that some children found some of the questions about their experiences of love, care, support and risky situations to be stressful. The study's OVC counsellors identified and counselled four such children and suggested steps they should take to address the problems, including where to go in case the problem recurs/persists. 
Data management and analysis: Qualitative data were analyzed by themes using the Nudist ${ }^{\circledR}$ software. Data collected through the questionnaire survey were entered using Epi-Data and analyzed using SPSS. The quantitative data were analyzed first through simple frequency distributions of the key indicators, disaggregated by gender and age. Secondly, a comparison was made based on the children's orphanhood status, through cross tabulations, difference of means, and, chi-square analyses, to determine whether there were any significant differences between orphans and non-orphans, and by gender and age. Further analyses were then undertaken if prompted by the findings.

Sample sizes achieved: As can be seen in Table 3, overall the sample size achieved was 38 respondents less than planned (approximately three percent), and with a slight over-representation of boys, and of younger children of both sexes. This was because older children were less likely to be found at home during the day (running errands, attending school, etc.). There was over-representation in Migori and Suba, and under-representation in Kisumu and Homa Bay. However, the findings can be considered representative of the study population, as these sample sizes are not too dissimilar to the study design.

Table 3: Study sample sizes by age and gender

\begin{tabular}{|r|c|c|c|c|c|c|c|}
\hline \multicolumn{1}{|l|}{ Age and sex } & Kisumu & Migori & $\begin{array}{l}\text { Homa } \\
\text { Bay }\end{array}$ & Suba & Total & Expected & Resp. rate \\
\hline Males 10-13 & 95 & 102 & 96 & 47 & 340 & 300 & $113 \%$ \\
Males 14-17 & $\mathbf{7 5}$ & 83 & 66 & 35 & 259 & 300 & $86 \%$ \\
Total Males & $\mathbf{1 7 0}$ & $\mathbf{1 8 5}$ & $\mathbf{1 6 2}$ & $\mathbf{8 2}$ & $\mathbf{5 9 9}$ & $\mathbf{6 0 0}$ & $99.8 \%$ \\
\hline Females 10-13 & 91 & 82 & 114 & 43 & 330 & 300 & $110 \%$ \\
Females 14-17 & 57 & 68 & 76 & 25 & 226 & 300 & $\mathbf{7 5 \%}$ \\
Total Females & $\mathbf{1 4 8}$ & $\mathbf{1 5 0}$ & $\mathbf{1 9 0}$ & $\mathbf{6 9}$ & $\mathbf{5 5 6}$ & $\mathbf{6 0 0}$ & $\mathbf{9 3 \%}$ \\
\hline Total children & $\mathbf{3 1 8}$ & $\mathbf{3 3 7}$ & $\mathbf{3 5 7}$ & $\mathbf{1 5 0}$ & $\mathbf{1 1 6 2}$ & & \\
\cline { 1 - 4 } Expected number & $\mathbf{3 3 0}$ & $\mathbf{3 1 9}$ & $\mathbf{4 1 2}$ & $\mathbf{1 3 8}$ & $\mathbf{1 2 0 0}$ & & \\
\hline Response rate & $\mathbf{9 6 \%}$ & $\mathbf{1 0 6 \%}$ & $\mathbf{8 7 \%}$ & $\mathbf{1 0 9 \%}$ & $\mathbf{9 7 \%}$ & & $\mathbf{9 7 \%}$ \\
\hline
\end{tabular}




\section{FINDINGS}

\section{Factors Perceived to Increase Children's Vulnerability}

The first stage of the study collected qualitative information from guardians, older children (10-17), community leaders, AAC representatives and service providers through group discussions, in-depth interviews and free-listing to identify community perceptions of those factors that may make children vulnerable to sexual and reproductive health risks, and whether they perceived any differences in vulnerability between OVCs and non-OVCs and between girls and boys. The key findings are described here, grouped into summary categories that emerged as the data were collected. Many of these issues were incorporated into the household survey questionnaires to be able to measure them quantitatively, and so more information is also available in the next section of the report.

\section{Economic factors:}

Poverty: Widespread poverty throughout the province was perceived by adults and children to be a major factor putting all children at risk. Inability to meet basic needs, rather than money per se, such as school fees and materials, food, clothing, bedding, soap and body/hair oil, was thought to motivate children to engage in transactional sex to be able to meet these needs. Respondents also felt that girls faced higher risks than boys, and that children who had been orphaned faced higher risks than children who had not been orphaned:
"Poverty at the family level may put children at risk. I would like to give a practical example of what happened in my own house. I have a child-aged 17 years. She had old shoes and schools were about to open. I told her to continue going to school with the old shoes as I looked for money. She went to school but when schools closed she did not come back home. She eloped with a young man whom she felt would provide her with new shoes. Two days after closure of school, I got worried when I did not see her. I started making follow-ups to know where she was....... A girl who goes to the same school with her directed me to a young man's house where she was. I probed her politely to know why she took the decision. She revealed to me that she was looking for new school shoes to use in school. That is why I am saying poverty in the house can lead a child into unbecoming behaviour. I just collected my daughter and went home." $\quad$ Female widowed caregiver

Engaging in income generating activities: Children from poor families, and especially orphan boys, are expected to bring income to the household, through activities such as fishing, sand harvesting, and bicycle transport. Some boys then use the money to entice girls into having sex, or for purchasing alcohol or drugs, which increases unsafe behaviours.

Additionally, the environment in which boys work can make them vulnerable to engaging in sex, voluntarily or through coercion; for example, boys involved in 
fishing were thought to engage in transactional sex with adult women working as fishmongers:

"Some of them (boys), after getting money from fishing, they use the money in taking alcohol...... and after taking alcohol you cannot know what is happening. You end up having sex with people whom you don't know, whether they are your mothers or sisters. So this is because of alcohol."

Male child

"Older female fishmongers hide in the beach to avoid inheritance. They give young boys in the beach money to have sex with them so that when they go back home they say they have been inherited." Male child

\section{Child-adult relationships}

Lack of love, care and parental guidance: Children who do not receive sufficient and appropriate love, care and guidance from their parents were perceived to be more likely to start being sexually active; this was thought to be especially true for orphans. Group discussions suggested that orphans were given more work and less affection than other children in their households, resulting in many feeling unloved by the family. It was felt that children feeling unloved, especially girls, become vulnerable to anyone who tells them they love them, and that a lack of parental guidance on responsible behaviours and close supervision can enhance this vulnerability. It can also lead some to run away from home and get married in search of better living conditions.

"An orphan is more at risk of pregnancy and STI infection because the uncle or aunt he/she stays with will not bother to advice and caution against these risks since he/she is not one of their own children. They only teach their own children."

Female child

"From what I have observed, some mothers don't advise orphans under their care. Even if an orphaned girl in her household becomes pregnant, she is not bothered. You can hear this same mother talking about this girl's pregnancy to a neighbour as if it does not concern her. She could say, 'imagine that daughter of my late brother-in law is pregnant.' Such mothers do not even advise the little girl on how to go about taking care of this pregnancy." Female guardian

Lack of supervision: Some common social events, such as village discos, funeral gatherings at night, and staying at school in the evening to do homework, can leave children unsupervised for significant periods of time, during which there are opportunities for both consensual and non-consensual sex. Children being left without adequate supervision were reported to be at risk, especially orphans whose caregivers may not take a keen interest in their wellbeing or whereabouts.

Sleeping arrangements: According to Luo (predominant ethnic community in the study areas) culture, when children (both male and female) reach adolescence they are not supposed to sleep in the same structure as their parents. Many sleep in the household kitchen (usually separate from the main house), or at a brother's, 
grandparent's or neighbour's house. Such sleeping arrangements were thought to give children the opportunity to sneak out at night for sexual encounters. In situations where children have to share the sleeping area with their parents, with or without a separating curtain, it was felt that children might hear or see their parents having sex and want to copy them. This situation affects both orphans and nonorphans.

\section{Cultural factors:}

Widow inheritance and sister replacement: These Luo customs were perceived to increase vulnerability for some boys and girls. Especially when the widows are young, the view was expressed that they may entice a boy, either a relative or nonrelative, to satisfy their sexual desires, as well as to perform the inheritance rite. Orphaned boys were perceived to be vulnerable to exploitative sexual relations with young widows as they lacked access to basic needs such as food and love, which some widows provide to entice them.

"I would like to point out that, today, young men die leaving behind young wives. The unfortunate thing is that our young sons aged 15-17 or older are the ones who inherit these women. It is not uncommon to find that the young widow is this boy's age mate. These young widows look for these boys but the boys also look for them to make a sexual relationship. This is what puts our children into these risks and no parental advice will stop them."

Female guardian

Young girls are sometimes required to marry their brother-in-laws if their married older sister dies. Not only may this increase their vulnerability to HIV infection, as is the case of boys performing widow inheritance, but it will also put them at risk of early pregnancy and childbirth. Girls, especially orphans, are viewed to be at risk of sister replacement because they may be willing to marry their widowed bother-inlaw if there is prospect of better living conditions, while others may be forced to do so by surviving parents or relatives, especially if the man is well off.

Early marriage: Age at marriage among the Luo is among the youngest in Kenya, especially for girls, which puts young girls at risk of an early pregnancy and of infection, especially if the man is much older, as is the norm. It was felt that many girls are expected or forced to marry at an early age, especially when there is no money in the family to support them to pursue secondary education. The general view among adults and children was that orphaned girls are more at risk of early marriage than non-orphans due to the lack of resources or unwillingness of their guardians to pay for secondary education. Young girls are often married off to reduce the number of dependants that a household head has to support.

Preferential treatment of boys: Preferential treatment of male children, and the perception that girls are temporary members of a family because they will get married and move elsewhere, were cited as factors increasing girls' vulnerability, and which can encourage girls to proactively seek ways of leaving the family and 
getting married early. It was felt that orphaned girls were especially likely to be discriminated against within a family and therefore at risk of getting married earlier.

"... some guardians follow the Luo tradition that believes girls are wild beasts who should find a home elsewhere. She is a sojourner in the very house or home where she is born. There is a saying that 'a girl's home is elsewhere.' In this community there is sex preference. Many parents bank on boys for future assistance than girls. Girls are often taken for granted. This is one source of problem that makes girls walk out of their homes easily and get into these risks." Male guardian/parent

Generally it was felt that female orphans were more vulnerable than non-orphans to these cultural beliefs and practices because they may not have someone within the household to protect them, or their caregivers may not have enough resources to continue their schooling, preferring to marry them off.

\section{Knowledge to reduce vulnerability:}

Children's source of knowledge: Some respondents, both children and adults, felt that children have enough knowledge about sexual and reproductive health and HIV / AIDS, through receiving education at school, or knowing someone who has become pregnant or sick or died from an AIDS-related illness. Others thought that young people do not have enough knowledge, as such information is not easily available in their communities and parents do not, or are not able to discuss such issues knowledgeably with children. Some parents reported discussing SRH and HIV / AIDS issues with their children, but felt the children did not listen to their advice. It was felt that orphans and non-orphans had equivalent levels of knowledge as they lived in the same community with same source of information.

\section{Relationships among children:}

Coercion and trickery: Several examples were given of girls being tricked or forced into having sex by their boyfriends or acquaintances. For example, a boy at school might have some money and buy a girl snacks, but then expect her to have sex with him. There were also reports of boys being tricked into having sex with young widows, usually starting with asking a boy to assist them with some household activities rewarded with a meal and a bath, which leads to sex. Orphan boys and boys from poor families were reported to be particularly at risk of such situations.

Peer Pressure: Direct and indirect pressure from other children reportedly encourages girls and boys to engage in sex. In particular, it was thought that girls who have engaged in transactional sex encourage others to do likewise to get money to buy fashionable clothes, perfumes and other non-essentials; orphan girls were viewed to be at greatest risk because they are more likely to lack many such items, as well as essential items.

"Me, what I see from orphan girls is that when they see fellow girls who have their parents with nice things, like good clothes, and they do not have, some indulge in prostitution to get such kind of clothes". Male child 


\section{Background Characteristics of Children}

Table 4 describes the socio-demographic characteristics of the 1,162 children interviewed during the questionnaire survey ${ }^{11}$. As anticipated, $35 \%$ of them were orphaned, of which slightly more (54\%) were boys than girls (46\%). Most had lost their father only, although one third of all orphans (more than one in ten of all children) had lost both parents. Overall, three-quarters of all children lived with their father and/or mother, with over half reporting their father as the head of their household. Virtually all orphans live with a relative, but less than half of orphans live with a father or mother, with the majority living with their mother, which is to be expected given the higher proportion of paternal rather than maternal orphans. Also unsurprising is the finding that orphans are much more likely to live with a grandparent or aunt/uncle, with no differences between girls and boys.

Table 4: Socio-demographic characteristics of respondents (\%)

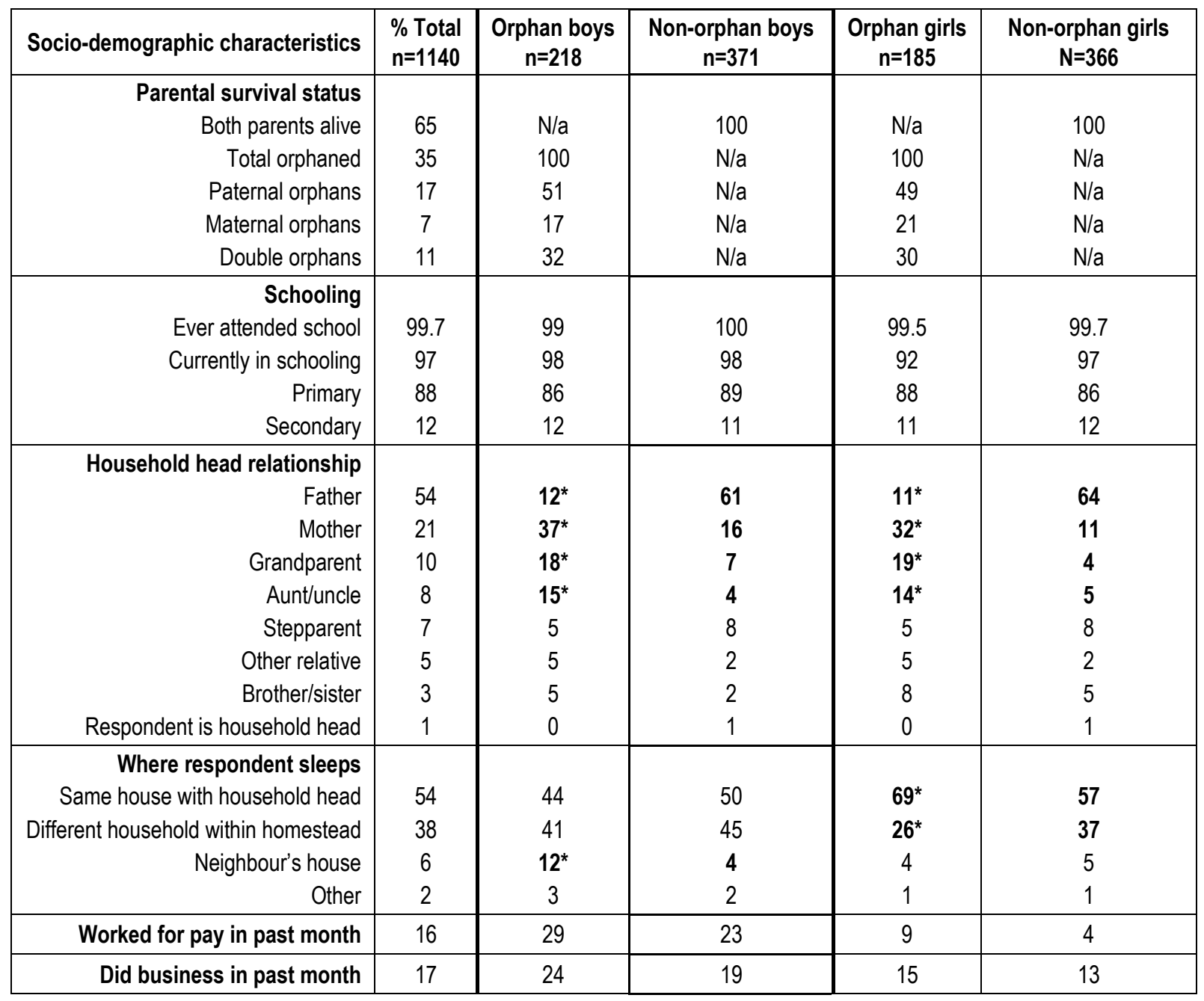

11 For this table, and for all analyses and tables that follow, statistically significant differences between groups are indicated in bold and by an*, indicating a difference at the 0.05 level. It is important to note, however, that for analyses of some variables and sub-groups, such as for sexual behaviour, the numbers in each sub-sample are small and so statistical comparisons are indicative and not conclusive. 
Most non-orphans live in father-headed households, whereas most orphans live in mother-headed households or with a grandparent or aunt/uncle; only half of maternal orphans, however, live with their father. The vast majority of children slept within their homestead, either in the household head's house or another household. Girls were more likely than boys (61\% vs. $48 \%)$ to sleep in the same house the household head, with girl orphans being the most likely of all children to do so. Few children slept outside the homestead, but boy orphans were the most likely to sleep in a neighbour's house.

Virtually all children had attended school and almost all were currently in school, with the majority being in primary school. Older female orphans (86\%) were the least likely to be in school.

Less than one in five children had engaged in income generating activities during the previous month, with more boys doing so than girls ( $26 \%$ vs. $5 \%)$, and more older than younger children (21\% vs. $12 \%)$. Orphaned children were somewhat more likely than non-orphaned children to have engaged in income generating activities, but the difference is not statistically significant.

Asked to rate their own health, three-quarters of children felt their health was good or very good, 18 percent rated their health as average, and only three percent felt their health was bad (three percent did not respond); there were no differences by age, sex or orphan status. Over 80 percent of all children reported having felt sick at some time in the past 12 months, and 97 percent of them or their parent/guardian took some action (no differences by age, sex or orphan status). 


\section{Exposure to Risky Behaviours}

\section{Sexual activity}

The older children aged 14-17 were asked a series of questions about their experiences of sexual activity, including exposure to situations that might put them at risk (see table 5). For all older children, 50 percent of boys and 37 percent of girls had ever had sexual intercourse. More orphans than non-orphans had ever had sex, among both boys and girls. This was particularly pronounced for girls whose mother has died, who were significantly more likely than girls with a living mother to have had sex (53\% vs. $34 \%)$.

Table 5: Sexual activity and preventive behaviours (\%)

\begin{tabular}{|c|c|c|c|c|}
\hline & $\begin{array}{c}\text { Orphan Boys } \\
n=107\end{array}$ & $\begin{array}{l}\text { Non-orphan } \\
\text { Boys } n=147\end{array}$ & $\begin{array}{c}\text { Orphan Girls } \\
n=75\end{array}$ & $\begin{array}{l}\text { Non-orphan } \\
\text { Girls } n=148\end{array}$ \\
\hline Ever had sex & 53 & 47 & 44 & 33 \\
\hline Ever had sex (n) & $n=57$ & $n=71$ & $n=33$ & $n=49$ \\
\hline Mean age at first intercourse & 12.5 & 12.5 & 13.2 & 13.8 \\
\hline $\begin{array}{r}\text { First sexual partner } \\
\text { Acquaintance } \\
\text { Stranger }\end{array}$ & $\begin{array}{l}88^{*} \\
12^{*}\end{array}$ & $\begin{array}{c}99 \\
1\end{array}$ & $\begin{array}{c}97^{*} \\
3^{*}\end{array}$ & $\begin{array}{l}88 \\
12\end{array}$ \\
\hline $\begin{array}{r}\text { Age of first sexual partner } \\
\text { Same age } \\
\text { Younger } \\
\text { Older }\end{array}$ & $\begin{array}{l}56 \\
21 \\
23 \\
\end{array}$ & $\begin{array}{l}57 \\
27 \\
16\end{array}$ & $\begin{array}{c}45 \\
3 \\
52 \\
\end{array}$ & $\begin{array}{c}41 \\
6 \\
53 \\
\end{array}$ \\
\hline Average no. of lifetime partners & 2.4 & 2.1 & 2.5 & 1.6 \\
\hline Ever use of contraceptives & 14 & 21 & 21 & 18 \\
\hline Ever use of condom & 15 & 14 & 21 & 13 \\
\hline Condom use at last sex by ever users & $69^{*}$ & 91 & $53^{*}$ & 85 \\
\hline
\end{tabular}

Among those children already sexually experienced, there was no difference between orphan boys and non-orphan boys in the age at first sex, but girl orphans were likely to have initiated sex over half a year earlier than girls who had not been orphaned. However, there was no difference between orphans and non-orphans, or between boys and girls, in the mean number of sexual partners since becoming sexually active (approximately two), and so this earlier age of debut may not substantially increase risk for children aged 14-17 years.

A major difference between orphans and non-orphans was in the relationship with their first sexual partner. Although the majority of all boys and girls reported that first sex was with someone they knew, orphan boys were much more likely than non-orphan boys to report having first had sex with a stranger (12\% vs. $3 \%)$, whereas non-orphan girls were much more likely than orphan girls to report first having sex with a stranger $(12 \%$ vs. $1 \%)$. 
Although orphans and non-orphans showed no differences in terms of the age of their first partner (for $57 \%$ of boys and $43 \%$ of girls they were the same age), as is the social norm in most cultures, girls were more likely to have older partners. Of importance, however, is the finding that boys whose mother has died were more than twice as likely as boys whose mother is alive (36\% vs. 15\%) to report having had first sex with an older partner. Moreover, 40 percent of boys whose mother had died reported having ever paid for sex (compared with $28 \%$ of boys with their mother alive), suggesting that for many of these boys who have lost their mothers, their first sex may have been transactional and with an older woman.

For three-quarters of boys, first sex was reportedly wanted, although seven percent reported it being forced; moreover, one in five boys reported having ever been forced into having sex when they didn't want to. Almost 20 percent of boys reported having ever forced someone to have sex against their will. All boys reporting forced sex mentioned that the person forcing them was a female.

As is unfortunately the norm for Kenya, for the majority of all girls their first sex was non-consensual. Moreover, 40 percent of all sexually experienced girls reported having ever been forced to have sex when they did not want to. Orphan girls were significantly less likely to have had non-consensual first sex than non-orphan girls (see Figure 1), and this decreased even further for girls whose mother had died, 45 percent of whom reported that they wanted to have first sex.

Figure 1: Reasons for first sex among girls

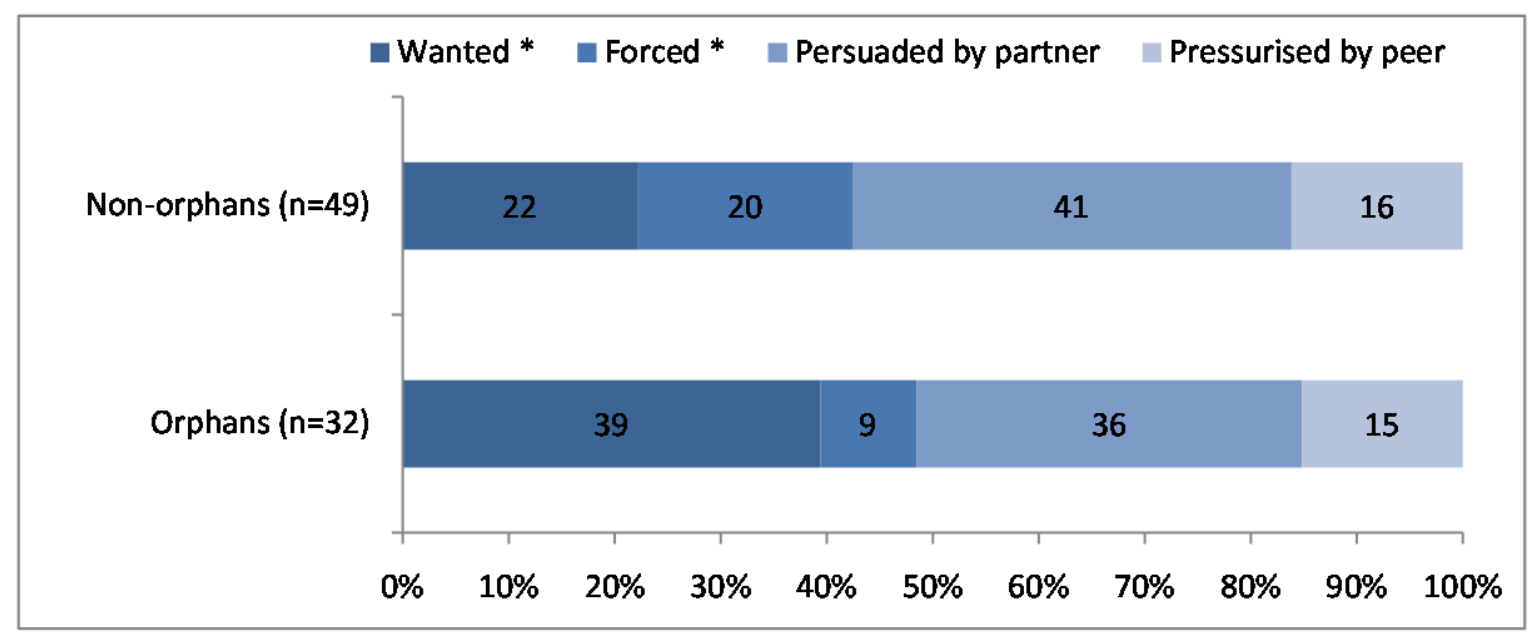

One half of all sexually experienced girls reported having ever received a gift, money or favours in exchange for sex, with a slightly higher proportion of orphan girls $(55 \%)$ than non-orphan girls (47\%) reported ever having transactional sex. This evidence offers some support to the idea that orphan girls may be at greater risk of engaging in transactional sex because they are more likely to need money or gifts to obtain basic needs. 
Unprotected sex was the norm, with use of condoms and other contraceptives being extremely low among all of those who had ever had sex, with no difference between orphans and non-orphans. Only 15 percent of girls and 13 percent of boys had ever used a condom or contraceptive. Among those who had ever used a condom, however, approximately three-quarters used one at last sex, although this was significantly lower among orphans than non-orphans, both boys (69\% vs. 91\%) and girls (53\% vs. $85 \%)$.

Significantly more children who had ever had sex (57 percent) perceived themselves to be at risk of infection with HIV or other STIs than those who had never had sex (30 percent), and so there seems to be some understanding that sexual activity can increase the risk of acquiring HIV; there were no differences by orphan status or sex.

\section{Peer pressure and risky situations}

All children were also asked a series of questions with specific questions asked to the older ones only (14-17) about peer pressure and other situations that might put them at increased risk of practising risky behaviours (Table 6). Clearly, many children feel at risk of peer pressure, and over half of both boys and girls do not feel confident to say no to sex, which supports the high levels of non-consensual sex being reported by girls as well as boys. These findings indicate, however, that orphans do not consider themselves to be any more pressured by their peers than non-orphans.

Two behaviours described in table 6, however, do potentially put orphans at greater risk of vulnerability because they were significantly more likely than non-orphans to report practising them: attending 'night activities' (such as discos, video shows, funerals, etc.) at which they may be unsupervised, and drinking alcohol. It is important to note that these risky behaviours were even more likely to be practised by boys and girls whose mother has died. Girls whose mother has died were more likely than girls with a living mother to report attending night activities (46\% vs. $27 \%$ ) and drinking alcohol (18\% vs. $7 \%$ ). Alcohol consumption was also much higher among boys whose mother has died, with such boys being more than twice as likely as boys with their mother alive (23\% vs. $11 \%)$ to have ever drunk alcohol.

Table 6: Children's exposure to risky situations (\%)

\begin{tabular}{|r|c|c|}
\hline & $\begin{array}{c}\text { Orphans } \\
\mathrm{N}=405\end{array}$ & $\begin{array}{c}\text { Non-orphans } \\
\mathrm{N}=742\end{array}$ \\
\hline Sometimes want to have certain things because peers have & 77 & 75 \\
\hline Feel confident that they can say no to sex if they do not want & & 40 \\
\hline Feel obliged to do things because others are doing them & 25 & 27 \\
\hline Feel obliged to do things because peers want them to & 22 & 21 \\
\hline Attended disco, video or other night activities in the past 12 months & $44^{*}$ & 36 \\
\hline Drunk alcohol & $17^{*}$ & 8 \\
\hline Smoked cigarettes, bhang or taken other drugs & 5 & 2 \\
\hline
\end{tabular}

** Only older children aged 14-17 answered these questions 


\section{Reproductive health conditions}

Among sexually active older children aged 14-17 years, four percent of orphans and 0.8 percent of non-orphans reported ever having an STI; there was no difference observed by sex. Among the girls, 15 percent reported ever having been pregnant, and four percent of boys reported having made a girl pregnant; there was no difference between orphans and non-orphans. Reported uptake of HIV testing was low. Twenty-five percent of sexually active non-orphan boys had tested for HIV compared to 18 percent of orphaned boys. Among the girls, 16 percent of nonorphans had ever tested for HIV compared to 9 percent of orphans.

\section{Knowledge of SRH and HIV/AIDS}

\section{Knowledge of fertility, family planning and STIs among older children}

As can be seen in table 7, knowledge about SRH issues was universally low among all children aged 14-17 years. Only 13 percent of older children knew that a woman is most likely to get pregnant in the middle of her cycle. When asked how a woman can prevent pregnancy, almost two-thirds of all respondents mentioned abstinence, with no significant differences by orphan status or sex. Condom use was mentioned by about one third of children, by boys more than girls, and by non-orphaned boys much more than orphaned boys. A little over ten percent of all children mentioned other contraceptives. Significantly higher proportions knew of any family planning method, however, with significantly more girls (42\%) than boys (26\%) knowing a method, but with no difference between orphans and non-orphans. Significantly more girls than boys knew of contraceptives, with the pill being the most well known method ( $85 \%$ of girls vs. $68 \%$ of boys) followed by injectables ( $48 \%$ vs. $19 \%$ ). Less than ten percent of children could mention other contraceptive methods such as implants and IUCD.

Table 7: Knowledge of fertility, family planning and STIs among older children

\begin{tabular}{|c|c|c|c|c|}
\hline Knowledge of: & $\begin{array}{l}\text { Orphan boys } \\
\qquad n=107\end{array}$ & $\begin{array}{c}\text { Non-orphan boys } \\
n=149\end{array}$ & $\begin{array}{c}\text { Orphan girls } \\
\qquad n=75\end{array}$ & $\begin{array}{l}\text { Non-orphan } \\
\text { girls } n=148\end{array}$ \\
\hline A woman's fertile period & 12 & 13 & 17 & 13 \\
\hline Any family planning method & 29 & 23 & 43 & 42 \\
\hline Any sexually transmitted infection & 84 & 82 & 84 & 87 \\
\hline \multicolumn{5}{|l|}{ How a woman can prevent pregnancy** } \\
\hline Abstinence & 64 & 56 & 55 & 66 \\
\hline Using condoms & 30 & 42 & 26 & 25 \\
\hline Other contraceptives & 9 & 11 & 13 & 13 \\
\hline Don't know & 9 & 11 & 13 & 9 \\
\hline \multicolumn{5}{|l|}{ Misconceptions - Think that: } \\
\hline A girl cannot get pregnant the first time she has sex & 26 & 32 & 32 & 32 \\
\hline A girl cannot get pregnant if has sex standing up & 16 & 18 & 28 & 19 \\
\hline
\end{tabular}

** Multiple responses given 
This disconnect between being able to name a method of family planning but not being able to cite contraception as a means of pregnancy prevention is a worrying indication of how poorly pregnancy prevention messages are being communicated generally, and interpreted by adolescents. The lack of accurate knowledge among these young people about sexuality and reproductive health is further evident in the findings that approximately 30 percent of all adolescents thought that a girl could not get pregnant the first time she has sex, and 20 percent that she cannot get pregnant if having sex standing up.

Conversely, awareness of STIs was universally high, at over 80 percent for all older adolescents. Moreover, over 80 percent knew that there are ways of preventing STIs, and about half knew that a person could have an STI without showing symptoms.

\section{Knowledge of HIV/AIDS}

Over 94 percent of all children had heard of HIV/AIDS; the six percent who did not were all in the younger age group (10-13 years). As table 8 shows, the vast majority of those who had heard of HIV mentioned sexual intercourse as a mode of transmission, with significantly more older than younger children mentioning this mode. Some form of sharp instrument was the second most mentioned mode, followed by blood contact, with non-orphan girls being significantly better informed than orphaned girls. Older orphaned girls, and especially those whose mother had died, were the least aware of the non-sexual modes of transmission. As would be expected, the highest proportion of those who did not know how HIV is transmitted was among the younger children (19 - 32 percent), and boys were less well aware than girls.

The vast majority of older children cited abstinence as a means of protection from HIV infection, with about one third mentioning condoms (boys knowing this method better than girls), and slightly less mentioning not sharing sharp instruments. Faithfulness (the ' $\mathrm{B}$ ' in conventional ' $\mathrm{ABC}$ ' strategies) is clearly not being communicated as a prevention strategy for these children. As with SRH issues, significant proportions of older children have misconceptions about HIV/ AIDS, five percent thought that it is possible to cure AIDS.

Table 8: Knowledge of HIVIAIDS among older children

\begin{tabular}{|r|c|c|c|c|}
\hline & $\begin{array}{c}\text { Orphan boys } \\
\mathbf{n = 2 1 8}\end{array}$ & $\begin{array}{c}\text { Non-orphan boys } \\
\mathbf{n = 3 7 1}\end{array}$ & $\begin{array}{c}\text { Orphan girls } \\
\mathbf{n = 1 8 5}\end{array}$ & $\begin{array}{c}\text { Non-orphan girls } \\
\mathbf{n = 3 6 6}\end{array}$ \\
\hline Know how one gets infected with HIV** & & & & 86 \\
\hline Sexual intercourse & 77 & 73 & 46 & $60^{*}$ \\
\hline Using un-sterilized sharp equipment & 54 & 47 & 24 & $35^{*}$ \\
\hline Blood contact & 31 & 31 & & 83 \\
\hline Anow how to protect self against HIV:* & & & 73 & 7 \\
\hline Faithfulness to one partner & 11 & 8 & 5 & 25 \\
\hline Condom use & 37 & 39 & 27 & $38^{*}$ \\
\hline Not sharing skin-piercing/sharp instruments & 21 & 27 & 26 & 23 \\
\hline Misconceptions - Think that: & & & & 16 \\
\hline HIV can be passed through mosquito bite & 22 & 14 & 19 & \\
\hline
\end{tabular}

** Multiple responses given 


\section{Sources of information about HIV/AIDS and SRH}

Most children indicated that they had received information on these topics, although 1-5 percent of older children and 8-15 percent of younger children said they had not. School was by far the most frequently mentioned source of information, especially for older children, with over 60 percent mentioning this; significantly fewer orphan girls $(62 \%)$ than non-orphan girls $(73 \%)$ mentioned school, possibly because they were less likely to be attending. Home and "the village" were also mentioned, but only by 25-30 percent of children for each, although orphans (26\%) were less likely than non-orphans (33\%) to mention the home, and especially orphan boys (20\%). Smaller proportions (20-22 percent) mentioned newspapers / radio, and about one in ten children mentioned the church. Younger respondents were more likely to mention other sources of information such as HIV/ AIDS campaigns, NGOs/CBOs in the community, and television for urban residents. Interviews with adults supported these findings:

"In schools, subject teachers handle issues on RH and HIVIAIDS and then we are also invited to give health talks" Health worker

"These reproductive health and HIV issues are usually broadcast over the radios, teachers also teach them at school how things are and how adolescents should behave. Health workers also educate the community and adolescents, so they get knowledge from there...." Female guardian/parent

"There are a lot of campaigns in the community. I have witnessed so many seminars held within communities through CBOs, FBOs and NGOs. Most of them are giving information about these risks". District Children's Officer

When asked from whom they learn SRH and HIV/AIDS information, teachers and health workers were the most commonly cited sources for over 70 percent of adolescents. Twice as many non-orphans as orphans (27\% vs.14\%) cited parents/guardians as an information source. This difference was even greater for older girl and boy orphans, among whom only 11 percent mentioned parents/guardians compared with 35 percent of older non-orphans, and especially for girls whose mother had died (6\% vs. 29\%). Pastors were mentioned by about 10 percent of adolescents, with no differences by age, sex or orphan status. Peers become an increasingly important source of information for older children, for about one third of all children (no differences by sex or orphan status). Among older boy and girl orphans, their peers are the second most cited source of this information after teachers, and for non-orphans they are about as important a source as their parents.

For younger children there is quite a difference, however, as health workers are the most cited source of information ( $40-46$ percent) and no differences by sex or orphan status, with teachers then parents/guardians being the second and third cited sources. This may be because of health workers visiting their schools to give 
talks, and/or because younger children may assume that anybody talking about health issues in the community is a health worker.

Focus group discussions with parents/guardians and with children demonstrated conflicting opinions about the degree and nature of parent-child discussions on these topics:

"We talk to the children about these issues but they do not take parental advice. We even tell them about AIDS related deaths, some of which they themselves have witnessed but they still don't care. At adolescent age they feel they know much more than the parents. They imagine they have a lot of experience and parents have very little advice to give them".

Female Guardian/parent

"They (parents) fear talking about these issues with children openly." Male child

"Parents just talk to their children to warn them but there is no discussion among them. The children just sit and listen, no talking."

Female child

"In our community, It's only women who talk to their young girls but boys...I doubt if their fathers talk to them because their fathers are very busy outside there. And it is these boys who deceive girls. If boys are not taught and girls are taught, then there'll still be a problem...." Female caregiver

When asked their preferred person from whom to learn about such matters, parents were the first preference for all children (64\%) especially for non-orphans (76\%) and for non-orphan girls (88\%), and for boys and girls whose mothers were alive. Teachers were the second preference for about one third of all children. Over one in five boy orphans mentioned their brother, especially older boys, and 17 percent of younger orphaned girls mentioned grandmothers. However, even for those orphans whose mothers have died, their parent (presumably the father), along with a teacher, was still the preferred source. Parents appear to support this, but are also keen for others to play a role in educating their children on these issues:

"A parent should teach his children, then the teacher second, then the church and also government officers" Female guardian/parent

"The youth should be taught through a combined effort. By getting the same information from different sources such as schools, churches, radio, chief's baraza, the youth may learn to do the right thing..." Female guardian/parent

Only about half of the children felt that their parent/guardian had adequate knowledge about pregnancy, STIs and HIV / AIDS, with fewer orphans than nonorphans feeling confident of their knowledge. However, only about one third of the children themselves felt adequately informed about pregnancy and STIs, and about 45 percent adequately informed about HIV/ AIDS. Children whose mother had died, 
and especially girls, were particularly lacking in confidence about their knowledge, with less than one in five feeling knowledgeable about pregnancy and STIs, and only 29 percent knowing about HIV/ AIDS. Qualitative data show mixed thoughts about whether or not orphanhood enhances lack of knowledge:

"Some orphans don't have enough knowledge because their caregivers do not allow them to go to school and mostly this knowledge is gained from school"

\section{Male child}

“'Orphans are just like us. We all don't have adequate information on reproductive health and $H I V$ "

Female child

\section{Psychosocial Support at Home}

Qualitative data suggested that children who did not receive love, support and guidance at home may be more vulnerable to risky situations and engaging in risky behaviours. Moreover, there was the perception that orphaned children may be more vulnerable because they could lack such psychosocial support through having only one parent or being with a guardian. As Table 9 indicates, the majority of respondents had someone at home they could talk to about their feelings, and felt treated equally with and liked by other children in their households. The data are not shown here, but girl orphans, and especially older girls and girls whose mother had died, were significantly less likely to have someone to talk with, to feel treated equally, to feel liked, and to feel they were given equal work.

Table 9: Familial support for children, by orphan status (\%)

\begin{tabular}{|c|c|c|c|c|}
\hline & $\begin{array}{c}\text { Orphan boys } \\
n=218\end{array}$ & $\begin{array}{c}\text { Non-orphan boys } \\
n=371\end{array}$ & $\begin{array}{c}\text { Orphan } \\
\text { girls } \\
n=185\end{array}$ & $\begin{array}{c}\text { Non- } \\
\text { orphan } \\
\text { girls } \\
\mathrm{n}=366\end{array}$ \\
\hline Have someone at home to talk with about their feelings & 63 & 70 & $59 *$ & 70 \\
\hline Feel liked very much by other children in the household & 56 & 59 & $45^{*}$ & 59 \\
\hline Feel treated equally to other children in the household & 71 & 82 & $71^{*}$ & 83 \\
\hline Given equal work to other children in the household & 69 & 76 & 66 & 71 \\
\hline Beaten at home in the past 12 months & $53^{*}$ & 62 & 49 & 58 \\
\hline Ridiculed/insulted at home the past 12 months & 44 & 45 & 45 & 51 \\
\hline
\end{tabular}

Orphaned boys and girls were less likely than non-orphans to report having been beaten in the previous 12 months. A couple of reasons may explain this. First, beating children with a cane is a common and socially approved form of discipline in these communities, and so not beating children may indicate that guardians pay less attention to the well-being of orphans, including disciplining them. Conversely, guardians may feel uneasy disciplining orphans who are not their own children, fearing that the children may interpret this as abusive rather than as a form of guiding the child. 
When asked about the amount of love that the child felt they received from the person they were closest to at home (see Table 10), orphans were less likely than non-orphans to feel that this person gave them a lot of love; this was especially the case for orphans whose mother had died (57\% compared with $68 \%$ for children whose mother was alive). Likewise, when asked about the amount of love shown by the head of household and by other children in the household, orphans, and especially maternal orphans, felt that they received significantly less love.

Table 10: Degree of love perceived by children, by orphan status (\%)

\begin{tabular}{|r|c|c|c|c|}
\hline & $\begin{array}{c}\text { Orphans } \\
\mathrm{n}=405\end{array}$ & $\begin{array}{c}\text { Non- } \\
\text { orphans } \\
\mathrm{n}=742\end{array}$ & $\begin{array}{c}\text { Mother } \\
\text { alive } \\
\mathrm{n}=944\end{array}$ & $\begin{array}{c}\text { Mother } \\
\text { dead } \\
\mathrm{n}=203\end{array}$ \\
\hline Closest person in household shows a lot of love & 62 & $68^{*}$ & 68 & $57^{*}$ \\
\hline Head of household shows a lot of love & 47 & 53 & 54 & $37^{*}$ \\
\hline Liked very much by other children in the household & 53 & $61^{*}$ & 60 & $48^{*}$ \\
\hline
\end{tabular}

Among the non-orphans who had someone at home they could talk to, their mother $(52 \%)$ and then father (32\%) were the most frequently mentioned; $27 \%$ mentioned a sibling. For orphans, however, the situation depended on who they live with; although their mother was still the most frequently cited (35\%), a sibling was the next $(23 \%)$, with grandmother and aunt/ uncle being mentioned by $15 \%$ each; only five percent of orphans mentioned their father, reflecting the small proportion living together.

The increased likelihood of orphan girls, and especially maternal orphans, being more likely to start sex earlier and to have consensual sex with an acquaintance, combined with their perception that they are less loved at home, may suggest that for some, becoming sexually active is a means of looking for love and affection that they feel they are not receiving at home.

\section{Access to Basic Needs}

The qualitative data revealed concerns that orphans, and particularly girl orphans, may have less access to basic needs and therefore may be susceptible to engaging in transactional sex to meet these needs, which may increase their vulnerability to sexual exploitation and abuse. To measure this potential vulnerability, children were asked which basic items their parents/guardians were able to provide them with most of the time (Table 11).

As Table 11 indicates, for all children there are many basic items that parents/guardians are not able to provide regularly, including food, bedding and schooling needs, illustrating the extreme poverty in which much of this population lives. The situation is worse for orphans; with the exception of bedding, boy or girl orphans are much less likely than non-orphans to be provided with all of these basic needs, and especially schooling related needs. 
Table 11: Proportion of children (\%) whose parents are able to provide for basic needs most of the time

\begin{tabular}{|r|c|c|c|c|}
\hline & $\begin{array}{c}\text { Orphan boys } \\
\mathrm{n=218}\end{array}$ & $\begin{array}{c}\text { Non-orphan boys } \\
\mathrm{n=371}\end{array}$ & $\begin{array}{c}\text { Orphan girls } \\
\mathrm{n=185}\end{array}$ & $\begin{array}{c}\text { Non-orphan girls } \\
\mathrm{n}=\mathbf{3 6 6}\end{array}$ \\
\hline Laundry soap & $\mathbf{5 7 ^ { * }}$ & $\mathbf{7 6}$ & 61 & $\mathbf{7 0}$ \\
\hline Bathing soap & $\mathbf{6 3 ^ { * }}$ & $\mathbf{7 6}$ & $\mathbf{5 7 ^ { * }}$ & $\mathbf{6 5}$ \\
\hline Body oil & $\mathbf{4 5}^{\boldsymbol{*}}$ & $\mathbf{6 2}$ & $\mathbf{5 0 ^ { * }}$ & $\mathbf{6 2}$ \\
\hline Enough food & $\mathbf{4 4}^{\boldsymbol{*}}$ & $\mathbf{6 2}$ & 57 & 64 \\
\hline School levies / fees & $\mathbf{2 3}^{*}$ & $\mathbf{3 9}$ & 25 & 33 \\
\hline School uniform & $\mathbf{3 7 ^ { * }}$ & $\mathbf{5 4}$ & $\mathbf{3 8 ^ { * }}$ & $\mathbf{5 2}$ \\
\hline Books & 22 & 29 & $\mathbf{1 6 ^ { * }}$ & $\mathbf{2 6}$ \\
\hline Clothes for church/special occasions & $\mathbf{2 4 ^ { * }}$ & $\mathbf{3 8}$ & 28 & 37 \\
\hline Bedding & 57 & 64 & 55 & 60 \\
\hline
\end{tabular}

Given that over 40 percent of non-orphan children reported not getting enough food most of the time, and that this figure rises significantly to 56 percent of orphan boys, the children's nutrition status was measured through using the proxy indicators of weight and height. To compare them, the mean weight (in kilograms) and mean height (in centimetres) by age, sex and orphan status were calculated and compared (see tables in appendix II). No statistically significant differences between orphans and non-orphans were found, suggesting that orphans are not likely to be any more malnourished than non-orphans. The lower proportions of orphan than non-orphan reporting that their guardians are able to provide them with enough food most and the lack of a difference in children's height and weight suggest that orphans are more likely to feel that things are difficult for them.

\section{Economic Status of Households}

Data to measure the economic status of households included in this survey used an abbreviated and simplified form of the economic index developed for and used in the 2003 KDHS. The KDHS index was constructed using household asset data covering information on household ownership of a number of consumer items ${ }^{12}$. For this analysis, the following eight assets held by the household were included as indicators of economic status:
- Electricity
- Radio
- Television
- Telephone
- $\quad$ Three or more rooms used for sleeping
- Flush toilet
- Own land on which house is built
- Cement flooring.
12 In the $2004 \mathrm{KDHS}$, each asset was assigned a weight generated through principal components analysis, and the resulting asset scores were standardized in relation to a normal distribution. Each household was then assigned a score for each asset and the scores were summed for each household; individuals were ranked according to the total score of the household in which they resided, and the sample was then divided into quintiles.


A simple index was then created in which each household was assigned a score from $0-8$, signifying the number of assets that it possessed, with zero representing the poorest households and eight the least poor households. A comparison was then made between households with and without an orphan present to see whether there were any differences between them in terms of economic status measured this way. For ease of analysis and interpretation, these nine categories were then combined into three levels of poverty: poorest ( $0-2$ assets); moderately poor ( $3-5$ assets); and least poor ( 6 - 8 assets). Table 12 describes the comparison between households for these three levels.

Table 12: Economic status of households by presence of an orphan (\%)

\begin{tabular}{|r|c|c|}
\hline & $\begin{array}{c}\text { Orphan Household } \\
\mathbf{n = 3 4 2}\end{array}$ & $\begin{array}{c}\text { Non-orphan household } \\
\mathbf{n = 3 8 7}\end{array}$ \\
\hline Poorest: 0-2 score & 44 & 40 \\
\hline Moderately poor: 3-4 score & 41 & 44 \\
\hline Least poor: 6-8 score & 14 & 16 \\
\hline
\end{tabular}

Overall, using these measures of household assets, there is little difference in the economic status of households that have an orphan compared with those that do not have an orphan. Those households with the least assets are slightly more likely to have an orphan, and this likelihood increases when households with none or one asset only are considered $-18 \%$ of households with orphans are in this category compared with only $11 \%$ of households without orphans. While it is not possible to conclude that orphans are more likely to be put at risk because they live in greater poverty than non-orphans, those orphans living in households that could be considered the poorest of the poor may need special attention to ensure that the household receives relevant economic support. 


\section{Summary of Key Findings}

To summarize, the key findings from the research described above that have implications for programmes seeking to address the holistic needs of older orphans and vulnerable children are as follows:

- The survey found that 35 percent of all children were orphaned, with 11 percent of children being double orphans. Virtually all orphans live with a relative, and most non-orphans live in father-headed households, whereas most orphans live in mother-headed households or with a grandparent or aunt/uncle; half of maternal orphans live with their father.

- The vast majority of children, including orphans, were currently in school. Less than one in five children had engaged in income generating activities recently, although orphans were slightly more likely to have done so than non-orphans.

- One half of all sexually active girls had engaged in transactional sex, with slightly more orphans than non-orphans. Girl orphans tended to start having sex earlier than non-orphan girls, but were not likely to have had more partners.

- Half of all older boys and more than one third of older girls had ever had sex; orphans were more likely than non-orphans have had sex, and especially for maternal orphans.

- For the majority of all sexually experienced girls, first sex was non-consensual especially among non-orphans. However, orphan girls were more likely than girls who are not orphaned to have consensual sex. This may reflect orphan girls desire to look for love outside the home environment as suggested in the qualitative results.

- Orphan boys whose mother has died are much more likely than other boys to report having first sex with someone older and having paid for sex, again suggesting a search for love outside the family environment as fewer reported the person closest to them at home or household head showing them a lot of love, or, possibly, involvement with widows as the qualitative data suggested.

- Unprotected sex was the norm for all sexually active children. Orphans were significantly less likely than non-orphans to have used a condom at last sex, thereby increasing their vulnerability to unwanted pregnancy and STI/HIV infection. There were no differences, however, between orphans and nonorphans in terms of experiencing pregnancy or an STI.

- Knowledge of SRH issues was universally poor among all children, regardless of age, sex or orphan status, although awareness of HIV/AIDS was universal. Most children knew of sexual transmission of HIV, and the majority cited abstinence as a means of protection; only one third mentioned condoms. Over 20 percent of children, however, had incorrect information about HIV transmission. 
- Schools were the most frequently mentioned source of information about SRH and HIV/ AIDS for all children. Older children get information mostly through teachers, but younger children mention health workers, probably through school visits and talks in the community. Parents/guardians were mentioned by about one third of older non-orphans, but by less than one in ten orphans. Peers are a source of information for one third of all older children.

- Qualitative and quantitative data indicate that parents are the preferred source of information, for adults and children, and especially for non-orphans. Over half of all children are concerned, however, that their parents/guardians have inadequate knowledge.

- The qualitative data indicated that lack of supervision and/or loving care by parents/guardians was perceived to be a key factor that increases vulnerability for orphans. Although the majority of all children felt that they had psychosocial support at home, orphan girls, and especially maternal orphans, were less likely to feel they had such support. Orphans were less likely to report being beaten at home, which this may reflect a lower level of parent/guardian supervision than for non-orphans.

- Orphans and non-orphans felt equally susceptible to peer pressure, but orphans were more likely to have engaged in risky social behaviours such as attending night activities and drinking alcohol, particularly among maternal orphans.

- There are no differences between orphans and non-orphans in terms of their height and weight for age.

- The qualitative data indicate that poverty is perceived to be a factor increasing all children's vulnerability to situations and behaviours that may put them at risk. Orphans are perceived to be at a higher risk of engaging in non-consensual transactional sex, especially girls, because of their poverty. Many children reported not being able to access a range of basic necessities, and orphans were more likely to report lacking these basic necessities, which may make them more vulnerable. Although overall there is little difference in the economic status of orphan and non-orphan households, the poorest of the poor households are somewhat more likely to have an orphan. 


\section{CONCLUSIONS AND PROGRAMMATIC RECOMMENDATIONS}

\section{Conclusions}

- Overall, there were few major differences between orphans and non-orphans in terms of their living conditions: virtually all live with a relative; are attending school; do not engage in income-generating activities; are poorly informed about $\mathrm{SRH}$ issues, lack many basic needs, and live in households of poor or average economic status.

- In terms of vulnerability to risky situations, adolescent orphans, and especially those who have lost their mother, are more likely to become sexually active earlier than non-orphans. Indeed, for girls and boys whose mother has died, there seems to be some evidence that they may be engaging in sex to seek love and affection that they may not be getting at home, with orphaned girls more likely to report having first sex consensually with an acquaintance, and orphaned boys to have paid for first sex with an older partner.

- Orphans and maternal orphans particularly, are much more likely to engage in night activities and drink alcohol, both of which are likely to increase their vulnerability, which may reflect insufficient supervision by their parent/guardian.

- As one girl noted: "Orphans are just like us. We all don't have adequate information on reproductive health and $H I V^{\prime \prime}$. Schools seem to be easiest point of contact for reaching all children with education, and yet parents are the preferred source but need to increase their knowledge.

\section{Programmatic Recommendations}

1. Although many orphans do not seem to feel less loved at home than nonorphans, some of their reported behaviours suggest that they may be engaging in sex as a way of finding love and affection that may be missing at home. The recommendation emerging from this evidence is that guardians of orphans, and particularly children whose mother has died, need to be aware of this possibility and should ensure that these children receive adequate support, guidance and love to reduce them feeling the need to seek sexual relationships that may put them at risk. How such a recommendation can be implemented through an orphan-support programme is a major challenge, however. One possibility that needs to be explored further is that guardians of orphans could feel that the child is another mouth to feed, thereby stretching the meagre family budget even further. In such cases, a cash transfer scheme targeted for the poorest of the poor guardians could alleviate this stress and thus increase the likelihood that the orphan will received sufficient love and support to prevent them seeking sex as a substitute. 
2. Strategies are urgently needed to reduce non-consensual / forced sex by boys and men against all girls. This vulnerability occurs equally for all children, regardless of orphan status - indeed, non-orphan girls are actually more likely to be subjected to non-consensual first sex with a stranger than orphan girls.

Whether an orphan support programme can address this particular vulnerability is debatable.

3. Transactional sex by girls is also universally high, although orphan girls appear slightly more likely to engage in sex for money, gifts or favours. Again, because this risky behaviour is not necessarily more acute among orphans, an orphan support programme may not be the appropriate mechanism through which it could be reduced. Orphans of both sexes do appear, however, to have less access to most basic needs than non-orphans, and so a cash transfer mechanism targeted to increase their access to such necessities has the potential to reduce an economic motivation to engage in sex.

4. Cash transfers could create divisions within communities, however, if those households hosting orphans and receiving cash transfers are not poorer than those without orphans, even after including an orphan child - as seems to be the situation in this setting. In such situations, it may become necessary to undertake some sort of 'means testing' to determine those households that are most in need of economic support when hosting an orphan.

5. As both orphans and non-orphans are equally likely to be in school, and schools are an acceptable channel for communicating information about risk reduction behaviours, any programme that strengthens the quantity and quality of education about SRH within the school environment would contribute to reducing the vulnerability of all children, including orphans. Information about pregnancy prevention through contraception, and HIV prevention through condom use and partner reduction, is particularly needed, especially among children pre-puberty. Parents/guardians are a preferred source for such information, among both orphans and non-orphans, and so efforts also need to be increased to ensure that they are able to educate the children they care for, and with accurate information about risk reduction behaviours.

6. For some of the data collected, especially concerning sexual behaviours and risks, the sample sizes are only large enough to make tentative conclusions. Larger samples collected through further research would be needed, however, for more detailed analyses and a better understanding of the factors determining and differentiating the vulnerability of orphans and non-orphans. 


\section{APPENDIX}

\section{Appendix I: List of Research Assistants}

1. George Odingo - Data collection supervisor

2. Wilkister A. Ombidi - Assistant supervisor

3. Michael Oketch Kibogo

4. Danmark Owuor

5. Tabitha Awino

6. Kosida Kimuma

7. Rebecca Naomi Oyare

8. Nyariono Yusto Nguka

9. Truphosa A. Okwar

10. George Odero Auko

11. Claris A. Ayieta

12. Evans Omondi Ondu

13. Obumba Joseph Omondi

14. Carolyn Ochieng Babu

15. John Ogutu Ndinya

16. Aneti Wangkyo Mboya

\section{Professional Counsellors}

1. Kenneth Otieno

2. Christine Odongo

3. Samson Onyango Wambisa

4. Bertha Ouma

5. Everlyne Atieno Weje 


\section{Appendix II: Children's Weight and Height}

Mean weight for age (kg)

\begin{tabular}{|c|c|c|c|c|}
\hline $\begin{array}{c}\text { Age } \\
\text { (years) }\end{array}$ & $\begin{array}{c}\text { Orphan boys } \\
\mathbf{n = 2 1 8}\end{array}$ & $\begin{array}{c}\text { Non-orphan boys } \\
\mathbf{n = 3 7 1}\end{array}$ & $\begin{array}{c}\text { Orphan girls } \\
\mathbf{n = 1 8 5}\end{array}$ & $\begin{array}{c}\text { Non-orphan girls } \\
\mathbf{n = 3 6 6}\end{array}$ \\
\hline 10 & 30.61 & 30.46 & 30.73 & 30.53 \\
\hline 11 & 33.76 & 32.32 & 36.33 & 35.79 \\
\hline 12 & 36.58 & 35.93 & 37.58 & 40.14 \\
\hline 13 & 38.75 & 37.38 & 42.04 & 46.07 \\
\hline 14 & 48.41 & 43.78 & 50.11 & 49.52 \\
\hline 15 & 51.23 & 52.08 & 53.69 & 52.72 \\
\hline 16 & 53.88 & 53.36 & 59.25 & 54.28 \\
\hline 17 & 58.50 & 61.98 & 57.00 & 59.19 \\
\hline
\end{tabular}

Mean height for age $(\mathrm{cm})$

\begin{tabular}{|c|c|c|c|c|}
\hline $\begin{array}{c}\text { Age } \\
\text { (years) }\end{array}$ & $\begin{array}{c}\text { Orphan boys } \\
\mathbf{n = 2 1 8}\end{array}$ & $\begin{array}{c}\text { Non-orphan boys } \\
\mathbf{n = 3 7 1}\end{array}$ & $\begin{array}{c}\text { Orphan girls } \\
\mathbf{n = 1 8 5}\end{array}$ & $\begin{array}{c}\text { Non-orphan girls } \\
\mathbf{n = 3 6 6}\end{array}$ \\
\hline 10 & 138.86 & 134.47 & 135.14 & 136.54 \\
\hline 11 & 138.94 & 136.82 & 141.33 & 141.92 \\
\hline 12 & 145.88 & 145.19 & 141.89 & 149.48 \\
\hline 13 & 148.82 & 148.96 & 149.39 & 153.76 \\
\hline 14 & 157.23 & 154.29 & 156.50 & 157.79 \\
\hline 15 & 163.10 & 160.21 & 154.65 & 160.03 \\
\hline 16 & 166.26 & 163.95 & 161.81 & 159.59 \\
\hline 17 & 167.93 & 168.00 & 159.29 & 163.08 \\
\hline
\end{tabular}


For more information, please contact

\author{
Population Council \\ General Accident Insurance Hse \\ P.O. Box 17643 \\ 00500 Nairobi, Kenya
}

Tel: +254 202713480 - 3

Fax: +254202713479

Email: info@pcnairobi.org 